\title{
Sex-Specific Associations of Androgen Receptor CAG Trinucleotide Repeat Length and of Raloxifene Treatment with Testosterone Levels and Perceived Stress in Schizophrenia
}

\author{
Samantha J. Owens ${ }^{a, b}$ Thomas W. Weickert ${ }^{a, b}$ Tertia D. Purves-Tyson ${ }^{a, b}$ Ellen Jia, b \\ Christopher White ${ }^{c}$ Cherrie Galletlyd,e Dennis Liu ${ }^{d, e}$ Maryanne O'Donnell ${ }^{b}$ \\ Cynthia Shannon Weickert ${ }^{a, b, f}$ \\ a Schizophrenia Research Laboratory, Neuroscience Research Australia, Sydney, NSW, Australia; b School of Psychiatry, \\ University of New South Wales, Sydney, NSW, Australia; ' Department of Endocrinology, Prince of Wales Hospital, \\ Randwick, NSW, Australia; 'Discipline of Psychiatry, School of Medicine, University of Adelaide, Adelaide, SA, Australia; \\ eNorthern Adelaide Local Health Network, Adelaide, SA, Australia; ${ }^{f}$ Department of Neuroscience and Physiology, \\ Upstate Medical University, Syracuse, NY, USA
}

\section{Keywords}

Polyglutamine - Psychiatric disorder - Sex steroids ·

Selective estrogen receptor modulator - Affective

symptoms

\begin{abstract}
Lower testosterone levels are associated with greater negative symptoms in men with schizophrenia. Testosterone signals via androgen receptor (AR). A functional variant in the AR gene (CAG trinucleotide repeat polymorphism) is associated with circulating testosterone and mood-related symptoms in healthy people. Raloxifene increases testosterone in healthy males and reduces symptom severity and improves cognition in schizophrenia; however, whether raloxifene increases testosterone in men with schizophrenia is unknown. We assessed the interaction of a functional AR gene variant and adjunctive raloxifene on peripheral testosterone and symptom severity in schizophrenia. Patients with schizophrenia (59 males and 38 females) participated in a randomized, double-blind, placebo-controlled, crossover trial of ad-
\end{abstract}

\section{KARGER}

(c) 2018 S. Karger AG, Basel

E-Mail karger@karger.com

www.karger.com/mnp junctive raloxifene (120 mg/day). Healthy adults (46 males and 41 females) were used for baseline comparison. Baseline circulating testosterone was decreased in male patients compared to male controls and positively correlated with CAG repeat length in male controls and female patients. Male patients with short, compared to long, CAG repeat length had higher stress scores. Raloxifene treatment increased testosterone in male patients, but was unrelated to AR CAG repeat length, suggesting that raloxifene's effects may not depend on AR activity. Sex-specific alterations of the relationship between AR CAG repeat length and testosterone suggest that altered AR activity may impact perceived stress in men with schizophrenia.

(c) 2018 S. Karger AG, Basel

\section{Introduction}

Sex differences in the risk and severity of schizophrenia suggest that sex steroid hormones may modulate the course and symptoms of the disorder [1]. Estrogens are
Cynthia Shannon Weickert, $\mathrm{PhD}$

Schizophrenia Research Laboratory, Neuroscience Research Australia 139 Barker Street, Margarete Ainsworth Building, Level 5

Randwick, NSW 2031 (Australia)

E-Mail c.weickert@neura.edu.au 
proposed as being neuroprotective in schizophrenia, but the role of testosterone is less clear [1,2]. Research examining peripheral testosterone in men with schizophrenia has reported either reduced levels [3-6] or no difference compared to healthy control samples [7-9]. Studies investigating the relationship between testosterone levels and schizophrenia symptom severity suggest that testosterone can mediate clinical aspects of the disorder. Low testosterone levels are associated with greater negative symptoms $[3,6,10,11]$, worse cognition [8], and impaired emotion processing $[12,13]$ in males with schizophrenia. A single clinical trial found that testosterone augmentation ameliorated negative symptoms in men with schizophrenia [14]. Together, these studies suggest that a deficit in circulating testosterone or brain response to testosterone may relate to functional impairments in males with schizophrenia. Some antipsychotic medications can cause hyperprolactinemia, which can alter feedback mechanisms within the hypothalamic-pituitary-gonadal (HPG) axis and decrease testosterone production $[15,16]$; however, hyperprolactinemia has also been found in antipsychotic-naive patients and suggests HPG axis dysfunction in people with schizophrenia $[17,18]$.

Sex steroid therapies aimed at ameliorating symptoms and improving cognition offer potential new treatments for patients with schizophrenia $[14,19,20]$; however, testosterone and estrogen may be contraindicated due to potential adverse effects, particularly in males [21, 22]. Raloxifene, a selective estrogen receptor (ER) modulator, acts as an ER agonist in the brain and in bone and as an antagonist in most other tissues [23]. Raloxifene has been trialed as an adjunctive pharmacological therapy for schizophrenia. Some studies, primarily in women with schizophrenia, have reported reduced positive [24-26] and negative symptoms $[25,27,28]$ or improved cognition $[29,30]$ with raloxifene, while one study found no changes in symptoms or cognition [31]. A meta-analysis also indicated improvements in positive, general, and total symptom severity with raloxifene administration in patients with schizophrenia [32]. We have previously found that adjunctive raloxifene treatment improved cognition [30] and enhanced neural activity during emotion processing $[33,34]$ in men and women with schizophrenia. Overall, most studies confirm a relatively beneficial effect of raloxifene in patients with schizophrenia, despite inconsistencies as to which clinical aspects (symptoms or cognition) are ameliorated by the drug [32, 35, 36]. Raloxifene increased sex steroid levels in healthy samples, including estrogen in women [37-39] and testosterone in men [40-43], although several studies found

Androgen Receptor CAG Repeat Length and Schizophrenia no change in testosterone levels in either sex with raloxifene treatment $[39,44-46]$. Modification of circulating testosterone levels may be a mechanism by which raloxifene elicits beneficial effects in patients with schizophrenia. Yet, the extent to which raloxifene can change circulating testosterone levels in schizophrenia has not been determined.

In brain cells, testosterone can signal either directly or after conversion to the more potent androgen dihydrotestosterone or after conversion to estrogen and estrogenlike steroids [47]. In the brain, both testosterone and dihydrotestosterone bind and signal through the androgen receptor (AR). Exon 1 of the AR gene contains a CAG trinucleotide repeat sequence coding for a polyglutamine tract with a normal range of $11-30$ repeats $[48,49]$. CAG repeat length is crucial to $\mathrm{AR}$ function as shorter length is associated with higher AR gene expression [50] and greater receptor activity $[51,52]$. Thus, CAG repeat length is a potential AR genetic variant that can interact with circulating testosterone to modify brain response to testosterone and possibly schizophrenia symptom severity. The genetic CAG repeat length in AR is positively associated with circulating testosterone levels in both healthy men [53-58] and women [59-61]. While lower circulating testosterone is often found in men with schizophrenia [3-6], whether genetic variation in AR CAG repeat length is related to testosterone levels in patients with schizophrenia remains unknown.

Studies in humans demonstrate an inhibitory effect of testosterone on the stress response and hypothalamic-pituitary-adrenal (HPA) axis function [62-65]. Rodent studies indicated that the inhibitory effect of testosterone on the stress response may be AR-mediated $[66,67]$, suggesting that this receptor may play a role in moderating stress in patients with schizophrenia. Genetic variation in the AR gene is also shown to be associated with affective symptoms. A series of studies in older males ( $\geq 50$ years of age) with psychosomatic conditions (exclusive of psychosis) [68-71] showed that longer AR CAG repeat length was associated with greater depressive symptoms $[68,69]$ and more anxiety [70]. Conversely, shorter AR CAG repeat length was found in adolescents with major depressive disorder $[72,73]$ and was associated with depression and anxiety symptoms in male patients [72]. Despite inconsistencies as to the directionality of associations, potentially due in part to differences in the age of subjects between studies, this research demonstrates that genetic variation in AR in the form of differences in CAG repeat length is correlated with affective symptoms. However, how this same genetic variant may be related to

Mol Neuropsychiatry 2019;5:28-41 DOI: $10.1159 / 000495062$ 
mood-related symptoms in schizophrenia has not been tested.

The present study assessed the interaction of AR CAG repeat length and raloxifene on peripheral testosterone levels and symptom severity in men and women with schizophrenia. We conducted a 13-week randomized, double-blind, placebo-controlled, crossover trial of adjunctive raloxifene $(120 \mathrm{mg} /$ day $)$ in people with schizophrenia [30]. We hypothesized that testosterone levels would be decreased in men with schizophrenia and that shorter CAG repeat length would be associated with (1) lower circulating testosterone in men and women with schizophrenia and (2) more affective symptoms in men with schizophrenia. Furthermore, we hypothesized that adjunctive raloxifene treatment would increase circulating testosterone levels in male patients with schizophrenia. We predicted that male patients with longer CAG repeat length would have a greater increase in testosterone and reduction in symptom severity with raloxifene treatment than male patients with shorter CAG repeat length, while there would be no difference in female patients administered raloxifene based on CAG repeat length.

\section{Subjects and Methods}

\section{Participants}

Ninety-seven patients (59 males, 38 females, age $20-50$ years) with a diagnosis of schizophrenia $(n=64)$ or schizoaffective disorder $(n=33)$ and 87 healthy controls (46 males, 41 females, age 20-51 years) were included in this study. Clinical diagnostic interviews were performed by a trained psychiatrist or psychologist using the Structured Clinical Interview for Diagnostic and Statistical Manual IV Axis I Disorders (DSM-IV) [74]. All patients met the DSM-IV criteria for schizophrenia or schizoaffective disorder and had been receiving antipsychotics for at least 1 year prior to the study. The frequency of male and female patients receiving each antipsychotic medication at baseline is shown in online supplementary Table 1 (for all online suppl. material, see www. karger.com/doi/10.1159/000495062). There were 29 male and 19 female patients receiving at least one prolactin-raising medication, with the balance of patients receiving prolactin-sparing antipsychotics (30 males and 19 females) (see online supplementary Table 1). A complete description of participants, exclusion criteria, and trial design has been published previously [30].

\section{Trial Design}

We conducted a 13-week, randomized, double-blind, crossover, placebo-controlled trial. Patients were randomized to receive either placebo or adjunctive raloxifene $(120 \mathrm{mg} /$ day $)$ in addition to their currently prescribed antipsychotic medication for the first 6-week phase of the trial. All patients then entered a 1-week "washout" phase. Following the washout phase, patients entered the second 6-week phase of the trial consisting of the alternate treatment (raloxifene or placebo) to that received during the first 6-week phase. Patients were assessed at baseline and after 6 and 13 weeks of treatment (raloxifene or placebo). Compliance was determined by self-report, percentage of pills returned, and hormonal blood assays. Both participants and study personnel were blind to treatment status. Studies have found improvements in symptom severity following oral administration of raloxifene at $120 \mathrm{mg}$ /day in postmenopausal women with schizophrenia $[24,26]$ and in men with schizophrenia [28], as well as improved cognitive ability in healthy older males and females $[75,76]$.

\section{Symptom and Negative Emotional State Ratings}

Symptom severity was evaluated using the Positive and Negative Syndrome Scale (PANSS) [77] and negative emotional states were evaluated using the 21-item version of the Depression Anxiety Stress Scale (DASS) [78]. The 21-item version of the DASS has proven validity and reliability in both general [79] and clinical [79, 80] samples. The DASS assesses mood-related symptoms and measures distinct features of depression (the absence of positive affect) and anxiety (physiological hyperarousal) as well as stress which encompasses common features of both depression and anxiety (irritability, persistent tension, and negative affect) [78-80].

\section{Blood Collection and Sex Steroid Hormone Measurement}

Fasting peripheral blood samples were collected from participants between 09:00 and 11:00 o'clock to control for diurnal variation. Blood samples were immediately clotted and heparinized and then delivered on ice to the Prince of Wales Hospital South Eastern Area Laboratory Services Pathology Unit, Randwick, Australia. A solid-phase competitive chemiluminescent immunometric assay (Siemens Immulite 2000) was used to measure serum testosterone levels for male patients at baseline and after 6 and 13 weeks of treatments and serum prolactin for male and female patients at baseline. The interassay coefficient of variation was $9.7 \%$ and the sensitivity of the assay was $0.7 \mathrm{nmol} / \mathrm{L}$ for testosterone. The interassay coefficient of variation was $6.8 \%$ and the sensitivity of the assay was $11 \mathrm{mIU} / \mathrm{mL}$ for prolactin. The plasma collected from female participants at baseline and after 6 weeks of treatment was stored at $-80^{\circ} \mathrm{C}$ until analyzed using stable isotope dilution liquid chromatography-tandem mass spectrometry (LC-MS/MS) as previously described [81]. LC-MS/MS was conducted at the ANZAC Research Institute, Concord, NSW, Australia. LC-MS/MS was used due to the lower levels of testosterone present in females [82] and the greater sensitivity and specificity of this method when measuring small amounts of steroidal compounds [81, 83, 84]. Circulating testosterone levels were measured once in healthy controls as a baseline comparison group. Measurements were determined blind to diagnosis and treatment.

\section{Genetic Analysis}

Genomic DNA was isolated as previously described [33]. Genotyping analysis of the AR gene CAG microsatellite was performed by Prevention Genetics, Marshfield, WI, USA or the Australian Genomic Research Facility, Melbourne, VIC, Australia. Control samples were analyzed by both facilities to ensure reliability of genotypes across sites. Briefly, for each participant 50 ng of DNA was used to amplify the AR gene by polymerase chain reaction using the FAM labeled forward primer $5^{\prime}$-TCC AGA ATC TGT TCC AGA GCG TGC- $3^{\prime}$ and the unlabeled reverse primer 5'-GCT GTG AAG GTT GCT GTT CCT CA-3'.
Owens et al. 
The fluorescently labeled DNA fragments were analyzed by size with automated capillary gel electrophoresis using an ABI3730 DNA Analyzer (Applied Biosystems Inc., Foster City, CA, USA). GeneMapper software (v4.1; Applied Biosystems Inc.) was used to quantify the length of the CAG repeat region from each sample.

The AR gene is located on the $\mathrm{X}$ chromosome and can be silenced by random inactivation of one of the two alleles present in females. Consequently, we averaged the two CAG repeat lengths for both alleles in females to account for heterozygosity. CAG repeat length was indeterminable or insufficient DNA was available for 8 healthy controls and 3 patients with schizophrenia. Unexpected expression of two alleles was found in one phenotypically male control (putative XXY), who was also excluded from genetic analyses. We stratified our participants into two groups based on the median values for all males (median $=21$ ) and females (median $=21.5$ ) to distinguish the upper and lower limits of CAG repeat length and created a two-level categorical variable: short $(\leq 21$ repeats; $n=78$ ) and long (>21 repeats; $n=94)$.

\section{Statistics}

Statistical tests were performed with IBM SPSS v23 (Armonk, NY, USA) and a $p$ value $<0.05$ was considered statistically significant. All analyses were performed separately on males and females.

Diagnosis and CAG Repeat Length Analyses. Baseline demographics were compared using two-way analysis of variance (ANOVA) with CAG repeat length groups (short and long) and diagnosis (patients and controls) as grouping factors and age and education as dependent factors. Baseline clinical variables (age at onset, illness duration, and mean daily chlorpromazine equivalent dose) were compared between CAG repeat length groups (short and long) for patients with schizophrenia using Mann-Whitney $U$ tests. Diagnostic differences of CAG repeat lengths were determined by independent-samples two-tailed $t$ tests for averaged CAG repeat length alleles and $\chi^{2}$ tests for CAG repeat length group frequency.

Testosterone Analyses. Outliers for testosterone measurements (0-1/group) were removed based on the Grubbs test (GraphPad Prism v7, La Jolla, CA, USA). Spearman's rank correlations were performed between baseline testosterone levels and demographics across all participants and with clinical characteristics and prolactin measurements in patients. Prolactin was measured to account for the prolactin-raising properties of some antipsychotic medications which can affect the HPG axis and decrease testosterone production $[15,16]$. Diagnostic differences in baseline testosterone levels were determined using the MannWhitney U test in males and using Quade's rank analysis of covariance in females (with age as a covariate) as baseline testosterone levels significantly correlated with age in females $(\rho=-0.25$, $p=0.03$ ). Spearman's rank correlations between baseline testosterone levels and CAG repeat length were performed separately in healthy controls, patients with schizophrenia, and patients with schizoaffective disorder. Fisher's $r$-to- $z$ transformation was used to detect differences between Spearman's $\rho$ correlation coefficients between baseline testosterone levels and CAG repeat length in patients with schizophrenia compared to schizoaffective disorder. Spearman's rank correlations were then performed with the diagnostic groups combined. We performed a parallel group analysis from baseline to end of week 6 (prior to crossover) using difference scores (week 6 minus baseline) of circulating testosterone levels in patients. Treatment effects on change in testosterone levels were analyzed using independent-samples two-tailed $t$ tests comparing patients receiving placebo to patients receiving raloxifene during the first 6 weeks of the trial (prior to crossover). Spearman's rank correlations between change in circulating testosterone levels during the first 6 weeks of the trial and CAG repeat length were performed separately for placebo- and raloxifene-treated patients.

Symptom and Negative Emotional State Analyses. In patients, baseline symptom and negative emotional state ratings were analyzed according to CAG repeat length group using independentsamples two-tailed $t$ tests or Mann-Whitney U tests for each symptom subscale score (PANSS: positive, negative, general, and total; DASS: depression, anxiety, and stress). Due to the evidence of period effects on PANSS positive, general, and total scores [30], we initially performed parallel group analyses (placebo: $n=37$; raloxifene: $n=40$ ) using only phase 1 difference scores (week 6 minus baseline) calculated for each symptom subscale. Parallel group analyses of treatment effects on change in symptoms were assessed using separate $2 \times 2$ ANOVAs with CAG repeat length group (short and long) and treatment group (raloxifene versus placebo) as grouping factors and change in PANSS positive, negative, and general as well as DASS depression, anxiety, and stress scores as dependent factors. To assess the effect of treatment in patients using the full crossover design, difference scores for each symptom subscale for both phases (phase 1: week 6 minus baseline; phase 2: week 13 minus week 6) were calculated. Crossover group analyses of treatment effects on change in symptoms were analyzed using a mixed-design ANOVA with treatment condition (raloxifene versus placebo), irrespective of phase, as the within-subjects factor, CAG repeat length group (short and long) as the between-subjects factor, and change in PANSS positive, negative, and general as well as DASS depression, anxiety, and stress scores as dependent factors.

\section{Results}

\section{Demographics and Clinical Characteristics}

The baseline demographics and clinical characteristics of the patients included in the adjunctive raloxifene treatment trial have been published previously [30]. The baseline demographics of patients and controls and the clinical characteristics of patients based on CAG repeat length groups by sex are shown in Table 1. Participants in this study displayed mild to moderate symptom severity as assessed by the PANSS. No significant differences between CAG repeat length groups were detected for demographic variables of controls and patients or for illness duration and mean daily chlorpromazine equivalent dose in patients. Statistical analyses detected a trend towards older age at disease onset in females in the short compared to the long CAG repeat length group $(p=0.051$; Table 1), but no effect of CAG repeat length group was found on age at disease onset in male patients (Table 1). 
Table 1. Baseline demographic variables and clinical characteristics of CAG repeat length groups by sex in schizophrenia patients and healthy controls

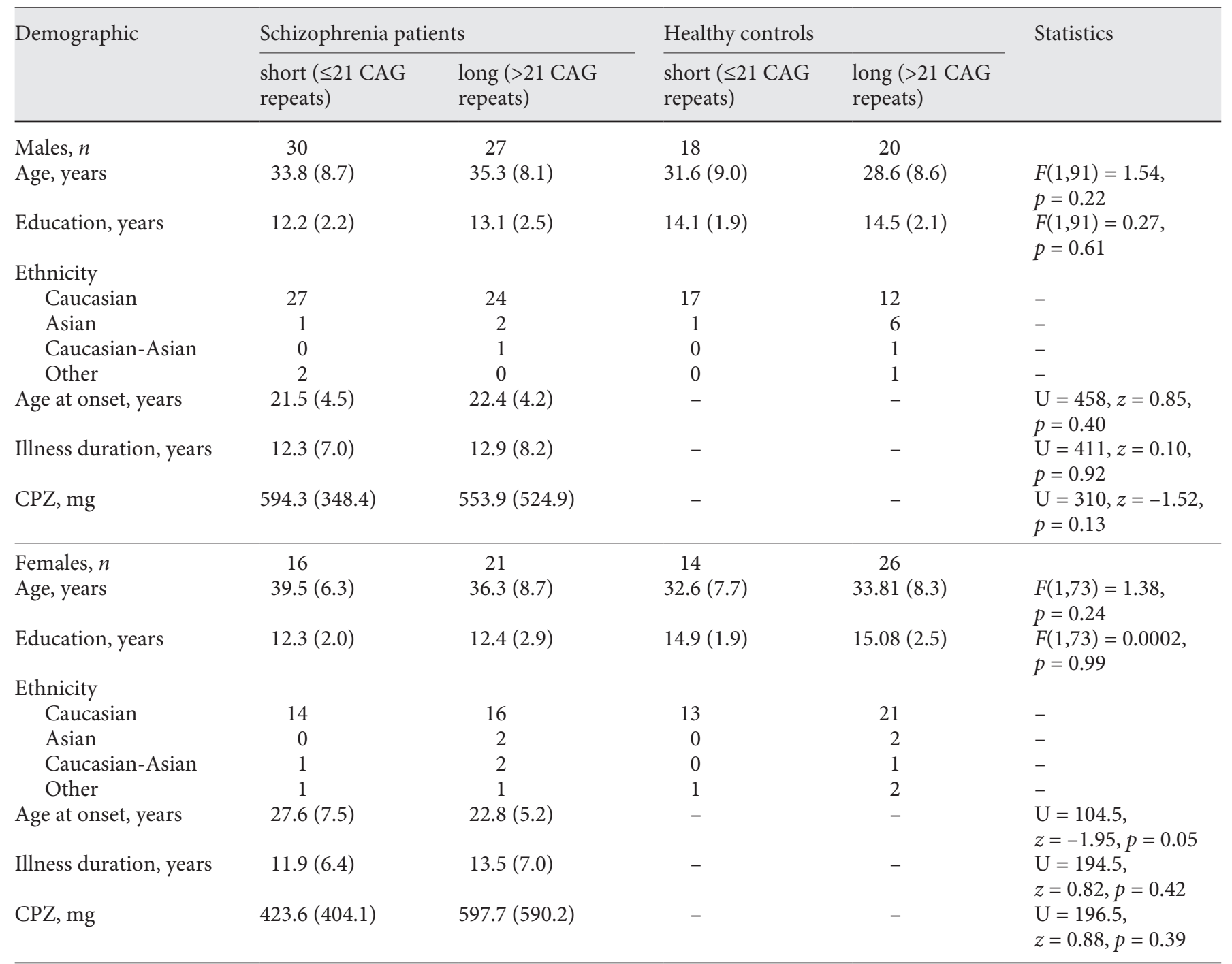

Data are mean (standard deviation) unless indicated otherwise. Demographic variables were analyzed using two-way analysis of variance (diagnosis $\times$ genotype), clinical variables using Mann-Whitney U tests. CPZ, mean daily chlorpromazine equivalent dose.

Fig. 1. Androgen receptor CAG trinucleotide repeat length frequency, baseline circulating testosterone levels, and correlations between CAG repeat length and baseline circulating testosterone in healthy controls and patients with schizophrenia. a, b Frequency distributions of androgen receptor CAG repeat length in our sample of males (a) and females (b) (see also Table 2). c, d Serum testosterone levels (data are mean \pm standard deviation) were significantly decreased in male patients with schizophrenia compared to male healthy controls $(\mathrm{U}=960.5, z=-2.09, p=0.04)(\mathbf{c})$, and trend level increased in female patients with schizophrenia compared to female healthy controls (Quade's rank analysis of covariance, $t[72]=1.72, p=0.09)(\mathbf{d})$. e-h In males, serum testosterone and CAG repeat length were significantly positively correlated in healthy controls (e) but not significantly correlated in patients $(\mathbf{g})$. In females, serum testosterone and CAG repeat length were not significantly correlated in healthy controls (f) but significantly positively correlated in patients $(\mathbf{h}) .{ }^{*} p<0.05,{ }^{* *} p<0.01,{ }^{\#} p<0.1$.

(For figure see next page.)
32

Mol Neuropsychiatry 2019;5:28-41 DOI: $10.1159 / 000495062$
Owens et al. 


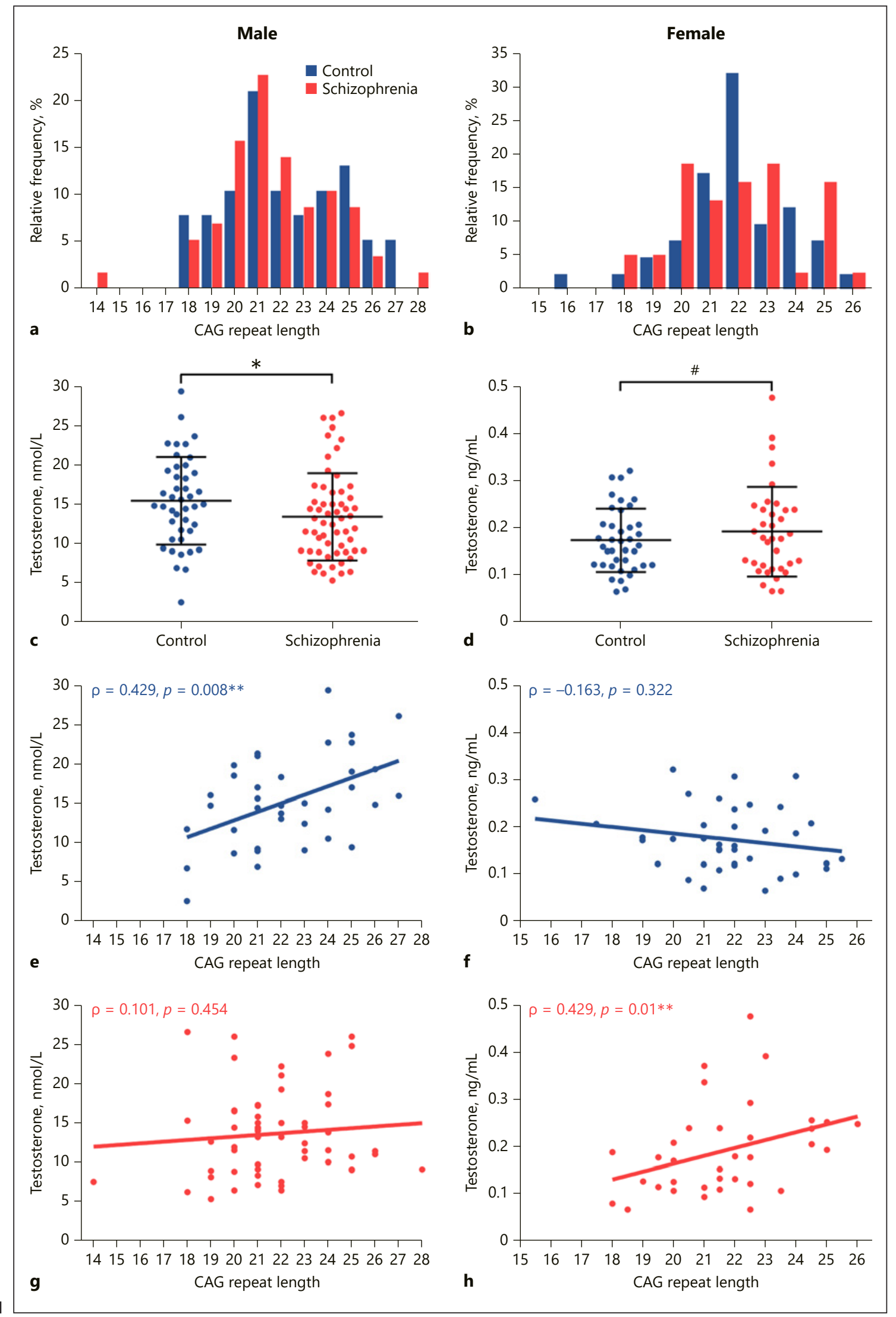


Table 2. Distribution of androgen receptor gene CAG repeat length for schizophrenia patients and healthy controls overall and separated by sex

\begin{tabular}{|c|c|c|c|c|c|c|c|c|}
\hline \multirow[t]{2}{*}{ Diagnosis } & \multirow[t]{2}{*}{$n$} & \multirow[t]{2}{*}{ Range } & \multirow[t]{2}{*}{ Median } & \multirow[t]{2}{*}{ Mean (SD) } & \multirow[t]{2}{*}{ Statistics } & \multicolumn{2}{|c|}{ CAG repeat length group, $n(\%)$} & \multirow[t]{2}{*}{ Statistics } \\
\hline & & & & & & $\begin{array}{l}\text { short }(\leq 21 \text { CAG } \\
\text { repeats) }\end{array}$ & $\begin{array}{l}\text { long }(>21 \mathrm{CAG} \\
\text { repeats) }\end{array}$ & \\
\hline \multicolumn{9}{|l|}{ Males } \\
\hline Controls & 38 & $18-27$ & 22 & $22.2(2.6)$ & \multirow[t]{2}{*}{$\begin{array}{l}t(93)=0.92 \\
p=0.36\end{array}$} & $18(47.4)$ & $20(52.6)$ & \multirow[t]{2}{*}{$\begin{array}{l}\chi^{2}=0.25, \mathrm{df}=1, \\
p=0.68\end{array}$} \\
\hline Schizophrenia & 57 & $14-28$ & 21 & $21.7(2.4)$ & & $30(52.6)$ & $27(47.4)$ & \\
\hline \multicolumn{9}{|l|}{ Females } \\
\hline Controls & 40 & $15.5-25.5$ & 22 & $21.7(2)$ & \multirow[t]{2}{*}{$\begin{array}{l}t(75)=0.10 \\
p=0.92\end{array}$} & $14(35.0)$ & $26(65.0)$ & \multirow[t]{2}{*}{$\begin{array}{l}\chi^{2}=0.55, \mathrm{df}=1, \\
p=0.49\end{array}$} \\
\hline Schizophrenia & 37 & $18-26$ & 21.5 & $21.7(2.1)$ & & $16(43.2)$ & $21(56.8)$ & \\
\hline \multicolumn{9}{|l|}{ Overall } \\
\hline Controls & 78 & $15.5-27$ & 22 & $22.0(2.3)$ & \multirow[t]{2}{*}{$\begin{array}{l}t(170)=0.74 \\
p=0.46\end{array}$} & $32(41.0)$ & $46(59.0)$ & \multirow[t]{2}{*}{$\begin{array}{l}\chi^{2}=1.08, \mathrm{df}=1, \\
p=0.36\end{array}$} \\
\hline Schizophrenia & 94 & $14-28$ & 21.5 & $21.7(2.3)$ & & $46(48.9)$ & $48(51.1)$ & \\
\hline
\end{tabular}

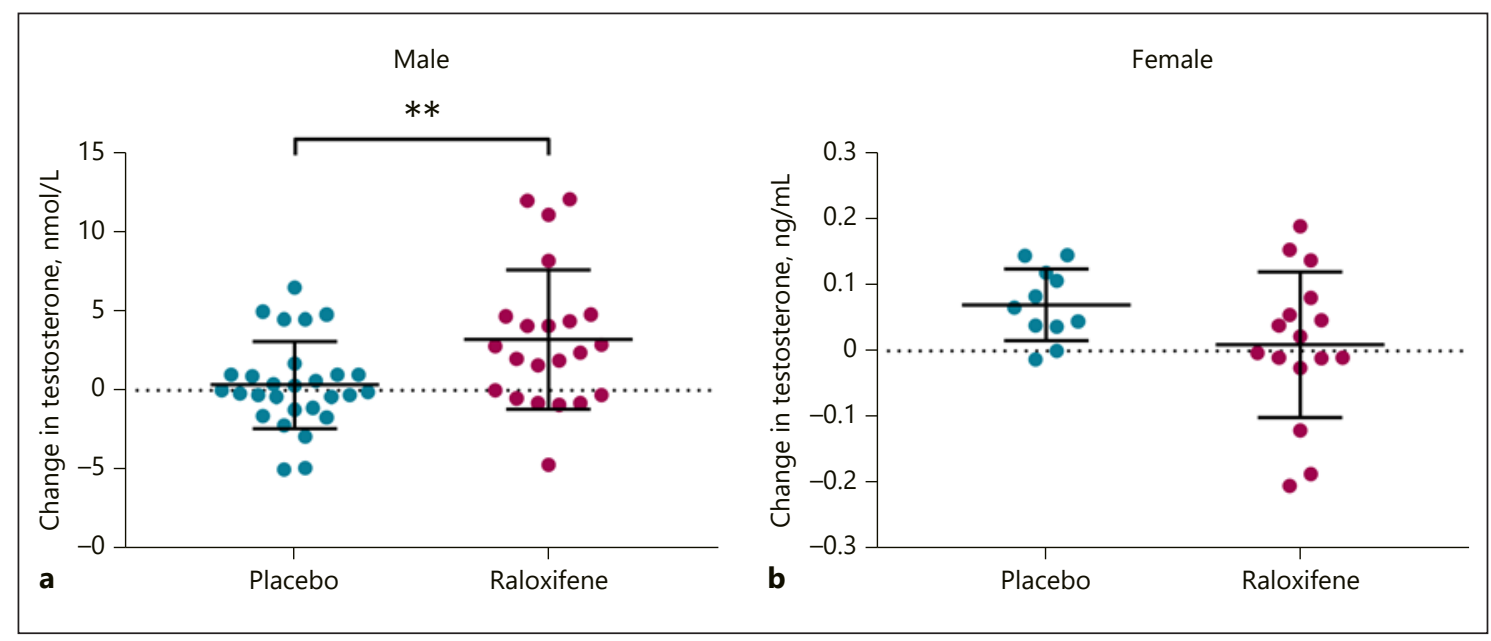

Fig. 2. Change in circulating testosterone levels with raloxifene treatment in patients with schizophrenia. Parallel group analyses found a significant positive increase in serum testosterone levels from baseline in male (a) $(t[48]=2.83, p=0.007)$ but not female $(\mathbf{b})(t[25]=1.68, p=0.11)$ patients with schizophrenia receiving adjunctive raloxifene treatment compared to placebo. Data are mean \pm standard deviation. ${ }^{* *} p<0.01$.

\section{AR CAG Repeat Length Frequency Was Not}

Associated with Diagnosis

The frequency distributions of averaged CAG repeat length alleles in patients and controls are shown in Figure $1 \mathrm{a}$ for males and in Figure $1 \mathrm{~b}$ for females. The averaged CAG repeat length in our sample ranged between 14 and 28 repeats, with $60 \%$ of samples between 20 and 23 repeats. We found no diagnostic difference overall or separately by sex between mean CAG repeat length or between the frequency of short and long CAG repeat length group (Table 2).

\section{Low Circulating Testosterone Levels in Males with Schizophrenia}

Baseline testosterone levels were significantly reduced by $13.1 \%$ in male patients compared to male controls $(\mathrm{U}=960.50, z=-2.09, p=0.04$; Fig. 1c). In contrast, baseline testosterone levels were not significantly changed in female patients compared to female controls, although statistical analyses suggested a trend towards a $10.5 \%$ increase in females with schizophrenia relative to female controls (Quade's rank analysis covarying for age, $t$ [72] = $1.72, p=0.09$; Fig. 1d). Baseline testosterone levels did not 
Table 3. Baseline symptom and negative emotional state scores in schizophrenia patients by CAG repeat length group

\begin{tabular}{|c|c|c|c|c|c|c|}
\hline Measure & \multicolumn{3}{|l|}{ Males } & \multicolumn{3}{|l|}{ Females } \\
\hline \multicolumn{7}{|l|}{ DASS } \\
\hline Depression & $13.7(10.2)$ & $10.1(8.6)$ & $\begin{array}{l}\mathrm{U}=319, z=-1.38 \\
p=0.17\end{array}$ & $10.8(7.4)$ & $13.8(11.0)$ & $\begin{array}{l}t(35)=0.96 \\
p=0.34\end{array}$ \\
\hline Stress & $16.4(9.0)$ & $11.0(7.7)$ & $t(55)=2.44, p=0.02^{*}$ & $12.4(9.4)$ & $17.5(11.1)$ & $\begin{array}{l}t(35)=1.50 \\
p=0.14\end{array}$ \\
\hline \multicolumn{7}{|l|}{ PANSS } \\
\hline Positive & $16.4(4.7)$ & $15.1(3.7)$ & $t(55)=1.14, p=0.26$ & $12.8(4.3)$ & $14.9(5.7)$ & $\begin{array}{l}t(35)=1.24 \\
p=0.22\end{array}$ \\
\hline Negative & $17.2(6.8)$ & $14.4(6.6)$ & $\begin{array}{l}\mathrm{U}=309, z=-1.54 \\
p=0.12\end{array}$ & $12.4(4.9)$ & $11.7(4.0)$ & $\begin{array}{l}t(35)=0.49 \\
p=0.62\end{array}$ \\
\hline
\end{tabular}

Data are mean (standard deviation). DASS, Depression Anxiety Stress Scale; PANSS, Positive and Negative Syndrome Scale. ${ }^{*} p<0.05$.

significantly correlate with prolactin levels in males $(\rho=$ $-0.11, p=0.41)$ or females $(\rho=-0.16, p=0.36)$ with schizophrenia.

\section{Sex-Specific Associations between AR CAG Repeat \\ Length and Circulating Testosterone Were Altered in \\ Patients with Schizophrenia}

Baseline testosterone levels and CAG repeat length were significantly and positively correlated in male controls $(\rho=0.429, p=0.008$; Fig. $1 \mathrm{e})$ and female patients $(\rho=0.429, p=0.01 ;$ Fig. $1 \mathrm{~h})$, but were not correlated in male patients $(\rho=0.101, p=0.454$; Fig. $1 \mathrm{~g})$ or female controls $(\rho=-0.163, p=0.322$; Figure 1f). There was no significant difference between correlations of baseline testosterone levels and CAG repeat length in patients with schizophrenia compared to patients with schizoaffective disorder in males $(z=-0.99, p=0.32)$ or females $(z=1.38, p=0.17)$.

\section{Males with Schizophrenia and Shorter AR CAG}

Repeat Length Had Greater Perceived Stress

Male patients in the short CAG repeat length group had significantly higher baseline DASS stress subscale scores than male patients in the long CAG repeat length group $(t[55]=2.44, p=0.02$; Table 3$)$. No significant effect of CAG repeat length group was detected on baseline PANSS subscale scores or DASS depression and anxiety scores in male patients (Table 3). In females with schizo- phrenia, there was no significant relationship between CAG repeat length and baseline PANSS or DASS subscale scores (Table 3 ).

\section{Adjunctive Raloxifene Treatment Increased}

Circulating Testosterone Levels but Did Not Interact with AR CAG Repeat Length to Change Symptoms in

Patients with Schizophrenia

When comparing placebo to raloxifene treatment in patients with schizophrenia, we showed significantly increased testosterone levels with raloxifene treatment in males $(t[48]=2.83, p=0.007$; Fig. 2a), but not females $(t[25]=1.68, p=0.11$; Fig. 2b). No significant correlations were detected between CAG repeat length and change in testosterone levels with placebo or raloxifene treatment in male (placebo: $n=27, \rho=-0.04, p=0.83$; raloxifene: $n=22, \rho=-0.17, p=0.45$ ) or female patients (placebo: $n=10, \rho=-0.23, p=0.52$; raloxifene: $n=16$, $\rho=0.1, p=0.72$ ). Parallel group and crossover group analyses comparing placebo and raloxifene treatment showed no main effects of CAG repeat length group (data not shown) or significant interactions between treatment (raloxifene and placebo) and AR genotype (short and long CAG repeat length groups) in male or female patient analyses for change in PANSS or DASS subscale scores (all $p>0.05$; see online suppl. Table 2 ). No serious adverse events were attributed to raloxifene during the trial, and the frequency of adverse events in 
$\geq 3 \%$ of patients was not significantly different between patients receiving raloxifene compared to those receiving placebo [30].

\section{Discussion}

We found low circulating testosterone levels in males with schizophrenia and a positive relationship between circulating testosterone and CAG repeat length in male controls and female patients, but no relationship in female controls and male patients. These findings indicate that the typical sex-specific relationship between an AR genotype and circulating testosterone levels [53-61] is disrupted in people with schizophrenia. We also found that short CAG repeat length in the AR gene predicted more stress symptoms in male patients, which suggests putative changes in stress signaling or stress buffering in this subset of men with schizophrenia. Finally, we found that adjunctive raloxifene treatment increased testosterone levels in male patients, and this was not related to AR CAG repeat length, suggesting that raloxifene may not be dependent on AR function for this effect.

Reduced testosterone levels are reported in chronically ill [3-6] and first-episode male patients with schizophrenia $[4,5]$ as well as prodromal adolescent males [85], suggesting that blunting of testosterone action may be related to schizophrenia etiology. Additionally, disease-related HPG axis alterations may act to reduce testosterone levels in schizophrenia. Correspondingly, we found reduced serum testosterone in male patients and a trend increase in female patients, indicative of altered, and potentially opposite, changes in androgen signaling in schizophrenia based on sex. Our finding builds on evidence that patients with schizophrenia have disrupted HPG axis function [3-5, 86-88], with potentially distinct effects in males and females. Decreased circulating testosterone may be deleterious in males and is supported by findings that low testosterone levels in men with schizophrenia are associated with greater negative symptoms $[3,6,10,11]$ and worse cognition [8]. Women have a slightly lower incidence of schizophrenia, milder symptoms, better treatment response, later age at onset, and are considered less adversely affected by schizophrenia than males $[2,86,87]$. Estrogen is considered neuroprotective in females with schizophrenia, and it is possible that increased testosterone in females also plays a neuroprotective role by buffering women against extreme symptom severity. However, the pathophysiological basis and the significance of the observed sex-specific alter- ations in circulating testosterone levels are yet to be elucidated.

AR CAG repeat length is a functional gene variant that may be capable of mediating levels of circulating testosterone in patients with schizophrenia. Our current finding in healthy men aligns with other well-powered studies that consistently reported a positive association between peripheral testosterone levels and CAG repeat length in healthy males [53-58] and has been proposed as a compensatory upregulation of testosterone with reduced AR functionality [56]. Circulating testosterone levels may vary with the number of CAG repeats to maintain homeostatic receptor activity both peripherally and in the brain. This normal feedback mechanism may be disrupted in men with schizophrenia, as no association between CAG repeat length and circulating testosterone was found in our male patient group. The differences in the correlations between CAG repeat length and peripheral testosterone in male patients and controls add to evidence of disturbed HPG axis function in patients with schizophrenia and suggest that the role of AR in the brain, with respect to negative feedback regulation, is altered in schizophrenia. The effect of disease-specific changes to overall androgen activity, and whether these are beneficial or detrimental in the brains of people with schizophrenia, remains uncertain and may be dependent on factors such as timing (for example, increased adolescent testosterone at the peak age at schizophrenia onset may be deleterious) $[1,89]$. Testosterone can affect multiple neurotransmitter systems, and how the effect of changes to androgen activity influences the brain is still being investigated [90].

This putative beneficial compensatory relationship between AR CAG repeat length and peripheral testosterone may exist in women with schizophrenia, as we found a significant positive correlation between CAG repeat length and circulating testosterone in our female patients. Alternatively, this relationship may be an atypical reaction for females, as we found no association between CAG repeat length and circulating testosterone in our female control group. However, research on the relationship between CAG repeat length and peripheral testosterone levels in healthy females reports inconsistent associations [59-61, 91-93]. Circulating testosterone levels in our female controls were low and within a narrow range $(0.06-0.3 \mathrm{ng} / \mathrm{mL})$, possibly limiting our ability to find a significant correlation with CAG repeat length. Thus, the disrupted relationship between CAG repeat length and testosterone may be deleterious in male patients, altering homeostatic androgen activity, while the positive rela-
Owens et al. 
tionship in females with schizophrenia may enable further regulation of androgen activity.

We also found that males with schizophrenia and short AR CAG repeat length, which has been associated with greater AR activity in experimental models [51, 52], had higher perceived stress (e.g., irritability, persistent tension, and negative affect). Studies in humans demonstrated an inhibitory effect of testosterone on the stress response and HPA axis function [62-65]. One of the largest studies to date found that prestress plasma testosterone levels were negatively associated with salivary cortisol response to psychosocial stress in healthy males [64]. Additionally, rodent studies showed that testosterone had an AR-mediated inhibitory effect on HPA axis function [66, 67] and an anxiolytic effect on behavior [94-96]. Given that we found reduced circulating testosterone levels in male patients, it is possible that decreased testosterone levels interact with CAG repeat length to reduce AR-mediated inhibition of the stress response and more strongly impact male patients with short CAG repeat length and greater AR activity. Our finding suggests that increased AR function could bias the brain to be more responsive to stress in males, but not females, with schizophrenia. Specifically, our results indicate that this functional AR gene variant may contribute to perception of stress and illness manifestation in a subset of male patients with shorter CAG repeat length and thus greater androgen "responsivity."

Research has found that a deficit in circulating testosterone may adversely affect symptoms $[3,6,10,11]$ and cognition [8] in men with schizophrenia, suggesting a beneficial effect of increased androgens, as demonstrated in a trial of testosterone augmentation therapy [14]. Hormone replacement therapy with testosterone has been shown to be beneficial in older hypogonadal men, improving sexual function and mild mood symptoms [97]; however, the potential long-term side effects, such as cardiovascular events and prostate cancer [22, 98], are risks of testosterone replacement therapy. Increased testosterone levels are an effect of raloxifene treatment in nonpsychiatric samples [40-43]. Thus, in addition to potentially stimulating abnormal ERs in the brains of people with schizophrenia [99], raloxifene has the potential benefit of increasing testosterone levels in patients with depleted circulating testosterone.

Here, we report that the present trial of adjunctive raloxifene treatment increased testosterone levels in male patients with schizophrenia. However, CAG repeat length, as an indirect measure of AR function in the brain, was not associated with changes in serum testosterone or

Androgen Receptor CAG Repeat Length

and Schizophrenia symptom severity, suggesting that raloxifene effects may not be dependent on AR function for increased testosterone and symptom reduction. The only trial of testosterone augmentation therapy in men with schizophrenia found that $5 \mathrm{~g}$ of $1 \%$ testosterone gel over a 4 -week period improved negative symptoms and increased total testosterone levels by an estimated mean of approximately $13 \mathrm{nmol} / \mathrm{L}$ [14]. In our study, the mean increase in circulating testosterone levels following raloxifene treatment from baseline in male patients was $3.2 \mathrm{nmol} / \mathrm{L}$ and, therefore, may not have reached the magnitude necessary to ameliorate symptoms. Additionally, patients in our study displayed mild to moderate symptom severity on the PANSS, which may limit the detection of changes in symptom response to treatment [36]. Moreover, the raloxifene-induced increase in circulating testosterone in male patients with schizophrenia may also act after conversion to estrogen [100], and additional assessment of testosterone's effects in relation to its conversion and interaction with other sex steroid hormones is warranted. Our group has previously shown molecular alterations to ERa in the frontal cortex of patients with schizophrenia [99], suggesting an abnormal brain response to sex steroids in a subgroup of people with schizophrenia. The primary action of raloxifene is tissue-dependent agonism or antagonism of ERs. We have shown that an ER genetic variant was related to increased cortical activation and accuracy during emotional inhibition in conjunction with adjunctive raloxifene treatment in patients with schizophrenia [33]. Thus, any restorative effects of increased testosterone on symptoms and cognition may be limited by the brain response to sex steroids in the disease state.

The current study has several limitations. We measured total serum or plasma testosterone and not free testosterone levels (unbound from sex-hormone-binding globulins); however, total and free testosterone levels are highly correlated, and both measurements are used as indicators of bioavailable levels $[3,10,101]$. The methods used to determine circulating testosterone levels also differed between sexes; however, it is important to note that all analyses were performed separately in men and women. Immunoassay was utilized for all male measurements as this method is considered to reliably detect testosterone levels in healthy eugonadal adult males [102]. LCMS/MS was used for all female measurements due to the lower levels of testosterone present in women and the greater specificity and sensitivity of this technique [83, 84]. The prolactin-raising properties of some antipsychotics may be a potential confounder in our study as

Mol Neuropsychiatry 2019;5:28-41 DOI: $10.1159 / 000495062$ 
hyperprolactinemia can alter HPG axis function and suppress production of testosterone in men and estrogen in women $[2,16]$; however, increased prolactin is also found in antipsychotic-naive patients $[17,18]$. Importantly, we found no strong, significant correlations between peripheral levels of testosterone and prolactin in males or females with schizophrenia, which suggests that prolactin levels were not a confounder in our study. Finally, a longer parallel design would enable assessment of the longlasting effects of raloxifene in the brain and prevent period and carryover effects that may confound the results of a crossover trial.

We found no association between CAG repeat length and schizophrenia diagnosis, and our current sample size may be underpowered to find genetic associations. Nonetheless, a larger study in Han Chinese patients with schizophrenia (patients: $n=225$; controls: $n=247$ ) found no association between CAG repeat length and schizophrenia diagnosis either [103]. We chose to focus on a single gene variant, which could be a limitation of the current study, as schizophrenia is a complex and heterogeneous disease that is thought to be polygenic, with multiple alleles from a variety of genes contributing to risk and genetic liability. Further consideration of our findings in the broader context of genetic variability within the disease can help to determine which relevant biological pathways these genetic changes converge on, possibly enabling the development of new treatment targets.

In summary, our findings of decreased peripheral testosterone in male patients and sex-specific alterations in the relationship between circulating testosterone and an AR genetic variant in schizophrenia indicate an imbalance in androgen activity in the disease state. Further, our finding that an AR genetic variant can impact perceived stress in male patients indicates the involvement of ARmediated mechanisms in putatively modifying schizophrenia symptom severity. Together, the results of our study support the hypothesis of abnormal sex steroid signaling in patients with schizophrenia $[1,99]$. Although we found that adjunctive raloxifene treatment increased circulating testosterone in men with schizophrenia, our results indicated that AR activity (indirectly measured as CAG repeat length) may not be a critical factor in predicting the effects of raloxifene in people with schizophrenia. Future investigations examining androgen-related molecules, such as the steroidogenic enzyme 5a-reductase, and AR gene variants in the brains of people with schizophrenia will help to clarify whether an abnormal response to testosterone exists in the disorder and will enable the

targeting of sex steroid modulating therapies to the specific patients who may derive the most benefit from sexsteroid-altering treatments.

\section{Acknowledgments}

The authors acknowledge use of the services and facilities of the Australian Genomic Research Facility (supported by the Commonwealth). This work was supported by NHMRC Project Grant No. 568807, the Australian Schizophrenia Research Bank, which is supported by the National Health and Medical Research Council of Australia, the Pratt Foundation, Ramsay Health Care, and the Viertal Charitable Foundation. C. Shannon Weickert is funded by the NSW Ministry of Health, Office of Health and Medical Research, and is a recipient of a National Health and Medical Research Council (Australia) Principal Research Fellowship (PRF) (\#1117079). S.J. Owens is supported by an Australian Government Research Training Program Scholarship and a Neuroscience Research Australia Scholarship.

\section{Statement of Ethics}

All participants provided written informed consent prior to participation in this study. The protocol was approved by the $\mathrm{Hu}$ man Research Ethics Committees of the University of New South Wales (07/121 and 09/187), the South Eastern Sydney and Illawarra Area Health Service (07-259), and the Queen Elizabeth Hospital, Adelaide, South Australia (2010188).

\section{Disclosure Statement}

C. Shannon Weickert is on an advisory board for Lundbeck, Australia Pty Ltd., and in collaboration with Astellas Pharma Inc., Japan. The authors declare no conflicts of interest in relation to this specific work.

References

Mol Neuropsychiatry 2019;5:28-41 DOI: $10.1159 / 000495062$
Owens et al. 
4 Huber TJ, Tettenborn C, Leifke E, Emrich HM. Sex hormones in psychotic men. Psychoneuroendocrinology. 2005 Jan;30(1):1114.

5 Taherianfard M, Shariaty M. Evaluation of serum steroid hormones in schizophrenic patients. Indian J Med Sci. 2004 Jan;58(1):3-9.

6 Goyal RO, Sagar R, Ammini AC, Khurana ML, Alias AG. Negative correlation between negative symptoms of schizophrenia and testosterone levels. Ann N Y Acad Sci. 2004 Dec; 1032(1):291-4.

7 Li J, Xiao W, Sha W, Xian K, Tang X, Zhang $\mathrm{X}$. Relationship of serum testosterone levels with cognitive function in chronic antipsychotic-treated male patients with schizophrenia. Asia Pac Psychiatry. 2015 Sep;7(3):323-9.

8 Moore L, Kyaw M, Vercammen A, Lenroot R, Kulkarni J, Curtis J, et al. Serum testosterone levels are related to cognitive function in men with schizophrenia. Psychoneuroendocrinology. 2013 Sep;38(9):1717-28.

9 Misiak B, Frydecka D, Loska O, Moustafa AA, Samochowiec J, Kasznia J, et al. Testosterone, DHEA and DHEA-S in patients with schizophrenia: A systematic review and meta-analysis. Psychoneuroendocrinology. 2018 Mar; 89:92-102.

10 Ko YH, Jung SW, Joe SH, Lee CH, Jung HG, Jung IK, et al. Association between serum testosterone levels and the severity of negative symptoms in male patients with chronic schizophrenia. Psychoneuroendocrinology. 2007 May;32(4):385-91.

11 Shirayama Y, Hashimoto K, Suzuki Y, Higuchi T. Correlation of plasma neurosteroid levels to the severity of negative symptoms in male patients with schizophrenia. Schizophr Res. 2002 Nov;58(1):69-74.

12 Ji E, Weickert CS, Lenroot R, Catts SV, Vercammen A, White C, et al. Endogenous testosterone levels are associated with neural activity in men with schizophrenia during facial emotion processing. Behav Brain Res. 2015 Jun;286:338-46.

13 Vercammen A, Skilleter AJ, Lenroot R, Catts SV, Weickert CS, Weickert TW. Testosterone is inversely related to brain activity during emotional inhibition in schizophrenia. PLoS One. 2013 Oct;8(10):e77496.

14 Ko YH, Lew YM, Jung SW, Joe SH, Lee CH, Jung HG, et al. Short-term testosterone augmentation in male schizophrenics: a randomized, double-blind, placebo-controlled trial. J Clin Psychopharmacol. 2008 Aug;28(4):37583.

15 Alosaimi FD, Fallata EO, Abalhassan M, Alhabbad A, Alzain N, Alhaddad B, et al. Prevalence and risk factors of hyperprolactinemia among patients with various psychiatric diagnoses and medications. Int J Psychiatry Clin Pract. 2018 Jan 15:1-8. doi: 10.1080/ 13651501.2018.1425459 [Epub ahead of print].
16 Bushe C, Shaw M, Peveler RC. A review of the association between antipsychotic use and hyperprolactinaemia. J Psychopharmacol. 2008 Mar;22(2 Suppl):46-55.

17 González-Blanco L, Greenhalgh AM, GarciaRizo C, Fernandez-Egea E, Miller BJ, Kirkpatrick B. Prolactin concentrations in antipsychotic-naïve patients with schizophrenia and related disorders: A meta-analysis. Schizophr Res. 2016 Jul;174(1-3):156-60.

18 Riecher-Rössler A, Rybakowski JK, Pflueger MO, Beyrau R, Kahn RS, Malik P, et al.; EUFEST Study Group. Hyperprolactinemia in antipsychotic-naive patients with first-episode psychosis. Psychol Med. 2013 Dec; 43(12):2571-82.

19 Kulkarni J, Gavrilidis E, Wang W, Worsley R, Fitzgerald PB, Gurvich C, et al. Estradiol for treatment-resistant schizophrenia: a largescale randomized-controlled trial in women of child-bearing age. Mol Psychiatry. 2015 Jun;20(6):695-702.

20 Kulkarni J, de Castella A, Headey B, Marston N, Sinclair K, Lee S, et al. Estrogens and men with schizophrenia: is there a case for adjunctive therapy? Schizophr Res. 2011 Feb;125(23):278-83.

21 Kulkarni J, Gavrilidis E, Worsley R, Van Rheenen T, Hayes E. The role of estrogen in the treatment of men with schizophrenia. Int J Endocrinol Metab. 2013;11(3):129-36.

22 Bhasin S, Cunningham GR, Hayes FJ, Matsumoto AM, Snyder PJ, Swerdloff RS, et al. Testosterone therapy in adult men with androgen deficiency syndromes: an endocrine society clinical practice guideline. J Clin Endocrinol Metab. 2006 Jun;91(6):1995-2010.

23 Muchmore DB. Raloxifene: A selective estrogen receptor modulator (SERM) with multiple target system effects. Oncologist. 2000; 5(5):388-92.

24 Kianimehr G, Fatehi F, Hashempoor S, Khodaei-Ardakani MR, Rezaei F, Nazari A, et al. Raloxifene adjunctive therapy for postmenopausal women suffering from chronic schizophrenia: a randomized double-blind and placebo controlled trial. Daru. 2014 Jul;22(1):55.

25 Usall J, Huerta-Ramos E, Iniesta R, Cobo J, Araya S, Roca M, et al. Raloxifene as an adjunctive treatment for postmenopausal women with schizophrenia: a double-blind, randomized, placebo-controlled trial. J Clin Psychiatry. 2011 Nov;72(11):1552-7.

26 Kulkarni J, Gurvich C, Lee SJ, Gilbert H, Gavrilidis E, de Castella A, et al. Piloting the effective therapeutic dose of adjunctive selective estrogen receptor modulator treatment in postmenopausal women with schizophrenia. Psychoneuroendocrinology. 2010 Sep;35(8): 1142-7.

27 Usall J, Huerta-Ramos E, Labad J, Cobo J, Núñez C, Creus M, et al.; RALOPSYCAT Group. Raloxifene as an Adjunctive Treatment for Postmenopausal Women With Schizophrenia: A 24-Week Double-Blind, Randomized, Parallel, Placebo-Controlled Trial. Schizophr Bull. 2016 Mar;42(2):309-17.
28 Khodaie-Ardakani MR, Khosravi M, Zarinfard R, Nejati S, Mohsenian A, Tabrizi M, et al. A placebo-controlled study of raloxifene added to risperidone in men with chronic schizophrenia. Acta Med Iran. 2015;53(6): 337-45.

29 Huerta-Ramos E, Iniesta R, Ochoa S, Cobo J, Miquel E, Roca M, et al. Effects of raloxifene on cognition in postmenopausal women with schizophrenia: a double-blind, randomized, placebo-controlled trial. Eur Neuropsychopharmacol. 2014 Feb;24(2):223-31.

30 Weickert TW, Weinberg D, Lenroot R, Catts SV, Wells R, Vercammen A, et al. Adjunctive raloxifene treatment improves attention and memory in men and women with schizophrenia. Mol Psychiatry. 2015 Jun;20(6):685-94.

31 Weiser M, Levi L, Burshtein S, Hagin M, Matei VP, Podea D, et al. Raloxifene Plus Antipsychotics Versus Placebo Plus Antipsychotics in Severely Ill Decompensated Postmenopausal Women With Schizophrenia or Schizoaffective Disorder: A Randomized Controlled Trial. J Clin Psychiatry. 2017 Jul; 78(7):e758-65.

32 de Boer J, Prikken M, Lei WU, Begemann M, Sommer I. The effect of raloxifene augmentation in men and women with a schizophrenia spectrum disorder: a systematic review and meta-analysis. NPJ Schizophr. 2018 Jan;4(1):1.

33 Kindler J, Weickert CS, Schofield PR, Lenroot $\mathrm{R}$, Weickert TW. Raloxifene increases prefrontal activity during emotional inhibition in schizophrenia based on estrogen receptor genotype. Eur Neuropsychopharmacol. 2016 Dec;26(12):1930-40.

34 Ji E, Weickert CS, Lenroot R, Kindler J, Skilleter AJ, Vercammen A, et al. Adjunctive selective estrogen receptor modulator increases neural activity in the hippocampus and inferior frontal gyrus during emotional face recognition in schizophrenia. Transl Psychiatry. 2016 May;6(5):e795.

35 Soria V, González-Rodríguez A, Huerta-Ramos E, Usall J, Cobo J, Bioque $\mathrm{M}$, et al.; PNECAT Group. Targeting hypothalamicpituitary-adrenal axis hormones and sex steroids for improving cognition in major mood disorders and schizophrenia: a systematic review and narrative synthesis. Psychoneuroendocrinology. 2018 Jul;93:8-19.

36 Weickert TW, Weickert CS. Raloxifene improves cognition in schizophrenia: spurious result or valid effect? Front Psychiatry. 2017 Oct;8:202.

37 Chatterton RT Jr, Zujewski J, Mateo ET, EngWong J, Jordan VC. Effect of raloxifene on salivary sex steroid concentrations in premenopausal women. J Endocrinol. 2006 Dec; 191(3):599-604.

38 Faupel-Badger JM, Prindiville SA, Venzon D, Vonderhaar BK, Zujewski JA, Eng-Wong J. Effects of raloxifene on circulating prolactin and estradiol levels in premenopausal women at high risk for developing breast cancer. Cancer Epidemiol Biomarkers Prev. 2006 Jun; 15(6):1153-8. 
39 Premkumar A, Venzon DJ, Avila N, Johnson DV, Remaley AT, Forman MR, et al. Gynecologic and hormonal effects of raloxifene in premenopausal women. Fertil Steril. 2007 Dec;88(6):1637-44.

40 Birzniece V, Sata A, Sutanto S, Ho KK. Neuroendocrine regulation of growth hormone and androgen axes by selective estrogen receptor modulators in healthy men. J Clin Endocrinol Metab. 2010 Dec;95(12):5443-8.

41 Birzniece V, Sutanto S, Ho KK. Gender difference in the neuroendocrine regulation of growth hormone axis by selective estrogen receptor modulators. J Clin Endocrinol Metab. 2012 Apr;97(4):E521-7.

42 Duschek EJ, Gooren LJ, Netelenbos C. Effects of raloxifene on gonadotrophins, sex hormones, bone turnover and lipids in healthy elderly men. Eur J Endocrinol. 2004 Apr; 150(4):539-46.

43 Uebelhart B, Herrmann F, Pavo I, Draper MW, Rizzoli R. Raloxifene treatment is associated with increased serum estradiol and decreased bone remodeling in healthy middleaged men with low sex hormone levels. J Bone Miner Res. 2004 Sep;19(9):1518-24.

44 Christodoulakos G, Lambrinoudaki I, Panoulis C, Sioulas V, Rizos D, Caramalis G, et al. Serum androgen levels and insulin resistance in postmenopausal women: association with hormone therapy, tibolone and raloxifene. Maturitas. 2005 Apr;50(4):321-30.

45 Doran PM, Riggs BL, Atkinson EJ, Khosla S. Effects of raloxifene, a selective estrogen receptor modulator, on bone turnover markers and serum sex steroid and lipid levels in elderly men. J Bone Miner Res. 2001 Nov; 16(11):2118-25.

46 Jirecek S, Lee A, Pavo I, Crans G, Eppel W, Wenzl R. Raloxifene prevents the growth of uterine leiomyomas in premenopausal women. Fertil Steril. 2004 Jan;81(1):132-6.

47 Celotti F, Negri-Cesi P, Poletti A. Steroid metabolism in the mammalian brain: 5alpha-reduction and aromatization. Brain Res Bull. 1997;44(4):365-75.

48 Casella R, Maduro MR, Lipshultz LI, Lamb DJ. Significance of the polyglutamine tract polymorphism in the androgen receptor. Urology. 2001 Nov;58(5):651-6.

49 Edwards A, Hammond HA, Jin L, Caskey CT Chakraborty R. Genetic variation at five trimeric and tetrameric tandem repeat loci in four human population groups. Genomics. 1992 Feb;12(2):241-53.

50 Choong CS, Kemppainen JA, Zhou ZX, Wilson EM. Reduced androgen receptor gene expression with first exon CAG repeat expansion. Mol Endocrinol. 1996 Dec;10(12):152735.

51 Chamberlain NL, Driver ED, Miesfeld RL. The length and location of CAG trinucleotide repeats in the androgen receptor $\mathrm{N}$-terminal domain affect transactivation function. $\mathrm{Nu}$ cleic Acids Res. 1994 Aug;22(15):3181-6.
52 Simanainen U, Brogley M, Gao YR, Jimenez M, Harwood DT, Handelsman DJ, et al. Length of the human androgen receptor glutamine tract determines androgen sensitivity in vivo. Mol Cell Endocrinol. 2011 Aug; 342(1-2):81-6.

53 Lindström S, Ma J, Altshuler D, Giovannucci E, Riboli E, Albanes D, et al. A large study of androgen receptor germline variants and their relation to sex hormone levels and prostate cancer risk. Results from the National Cancer Institute Breast and Prostate Cancer Cohort Consortium. J Clin Endocrinol Metab. 2010 Sep;95(9):E121-7.

54 Haring R, Ernst F, Schurmann C, Homuth G, Völker U, Völzke H, et al. The androgen receptor CAG repeat polymorphism as a risk factor of low serum testosterone and its cardiometabolic effects in men. Int J Androl. 2012 Aug;35(4):511-20.

55 Crabbe P, Bogaert V, De Bacquer D, Goemaere S, Zmierczak H, Kaufman JM. Part of the interindividual variation in serum testosterone levels in healthy men reflects differences in androgen sensitivity and feedback set point: contribution of the androgen receptor polyglutamine tract polymorphism. J Clin Endocrinol Metab. 2007 Sep;92(9):3604-10.

56 Huhtaniemi IT, Pye SR, Limer KL, Thomson W, O’Neill TW, Platt H, et al.; European Male Ageing Study Group. Increased estrogen rather than decreased androgen action is associated with longer androgen receptor CAG repeats. J Clin Endocrinol Metab. 2009 Jan; 94(1):277-84

57 De Naeyer H, Bogaert V, De Spaey A, Roef G Vandewalle S, Derave W, et al. Genetic variations in the androgen receptor are associated with steroid concentrations and anthropometrics but not with muscle mass in healthy young men. PLoS One. 2014 Jan;9(1):e86235.

58 Krithivas K, Yurgalevitch SM, Mohr BA, Wilcox CJ, Batter SJ, Brown M, et al. Evidence that the CAG repeat in the androgen receptor gene is associated with the age-related decline in serum androgen levels in men. J Endocrinol. 1999 Jul;162(1):137-42.

59 Durdiaková J, Celec P, Laznibatová J, Minárik G, Ostatníková D. Testosterone metabolism: a possible biological underpinning of nonverbal IQ in intellectually gifted girls. Acta Neurobiol Exp (Warsz). 2016;76(1):66-74.

60 Nowak NT, Diamond MP, Land SJ, Moffat SD. Contributions of sex, testosterone, and androgen receptor CAG repeat number to virtual Morris water maze performance. Psychoneuroendocrinology. 2014 Mar;41:13-22.

61 Westberg L, Baghaei F, Rosmond R, Hellstrand $M$, Landén $M$, Jansson $M$, et al. Polymorphisms of the androgen receptor gene and the estrogen receptor $\beta$ gene are associated with androgen levels in women. J Clin Endocrinol Metab. 2001 Jun;86(6):2562-8.
62 Hermans EJ, Putman P, Baas JM, Gecks NM, Kenemans JL, van Honk J. Exogenous testosterone attenuates the integrated central stress response in healthy young women. Psychoneuroendocrinology. 2007 Sep-Nov;32(810):1052-61.

63 Rubinow DR, Roca CA, Schmidt PJ, Danaceau MA, Putnam K, Cizza G, et al. Testosterone suppression of CRH-stimulated cortisol in men. Neuropsychopharmacology. 2005 Oct;30(10):1906-12.

64 Stephens MA, Mahon PB, McCaul ME, Wand GS. Hypothalamic-pituitary-adrenal axis response to acute psychosocial stress: effects of biological sex and circulating sex hormones. Psychoneuroendocrinology. 2016 Apr;66:4755.

65 Uhart M, Chong RY, Oswald L, Lin PI, Wand GS. Gender differences in hypothalamic-pituitary-adrenal (HPA) axis reactivity. Psychoneuroendocrinology. 2006 Jun;31(5): 642-52.

66 Handa RJ, Nunley KM, Lorens SA, Louie JP, McGivern RF, Bollnow MR. Androgen regulation of adrenocorticotropin and corticosterone secretion in the male rat following novelty and foot shock stressors. Physiol Behav. 1994 Jan;55(1):117-24.

67 Viau V, Meaney MJ. Testosterone-dependent variations in plasma and intrapituitary corticosteroid binding globulin and stress hypothalamic-pituitary-adrenal activity in the male rat. J Endocrinol. 2004 May;181(2):22331.

68 Schneider G, Nienhaus K, Gromoll J, Heuft G Nieschlag E, Zitzmann M. Aging males' symptoms in relation to the genetically determined androgen receptor CAG polymorphism, sex hormone levels and sample membership. Psychoneuroendocrinology. 2010 May;35(4):578-87.

69 Schneider G, Nienhaus K, Gromoll J, Heuft G Nieschlag E, Zitzmann M. Depressive symptoms in men aged 50 years and older and their relationship to genetic androgen receptor polymorphism and sex hormone levels in three different samples. Am J Geriatr Psychiatry. 2011 Mar; 19(3):274-83.

70 Schneider G, Nienhaus K, Gromoll J, Heuft G, Nieschlag E, Zitzmann M. Sex hormone levels, genetic androgen receptor polymorphism, and anxiety in $\geq 50$-year-old males. J Sex Med. 2011 Dec;8(12):3452-64.

71 Schneider G, Zitzmann M, Gromoll J, Ladwig $\mathrm{KH}$, Berger K. The relation between sex hormone levels, the androgen receptor CAGnpolymorphism and depression and mortality in older men in a community study. Psychoneuroendocrinology. 2013 Oct;38(10):208390.

72 Su QR, Su LY, Su HR, Chen Q, Ren GY, Yin $\mathrm{Y}$, et al. Polymorphisms of androgen receptor gene in childhood and adolescent males with first-onset major depressive disorder and association with related symptomatology. Int $\mathrm{J}$ Neurosci. 2007 Jul;117(7):903-17. 
73 Geng YG, Su QR, Su LY, Chen Q, Ren GY, Shen SQ, et al. Comparison of the polymorphisms of androgen receptor gene and estrogen $\alpha$ and $\beta$ gene between adolescent females with first-onset major depressive disorder and controls. Int J Neurosci. 2007 Apr;117(4): 539-47.

74 First MB, Williams JB, Spitzer RL, Gibbon M. Structured Clinical Interview for DSM-IVTR Axis I Disorders, 1st revision. New York, NY, USA, Biometrics Research Department, New York State Psychiatric Institute, 2007.

75 Goekoop R, Duschek EJ, Knol DL, Barkhof F, Netelenbos C, Scheltens P, et al. Raloxifene exposure enhances brain activation during memory performance in healthy elderly males; its possible relevance to behavior. Neuroimage. 2005 Mar;25(1):63-75.

76 Yaffe K, Krueger K, Cummings SR, Blackwell T, Henderson VW, Sarkar S, et al. Effect of raloxifene on prevention of dementia and cognitive impairment in older women: the Multiple Outcomes of Raloxifene Evaluation (MORE) randomized trial. Am J Psychiatry. 2005 Apr;162(4):683-90.

77 Kay SR, Fiszbein A, Opler LA. The Positive and Negative Syndrome Scale (PANSS) for schizophrenia. Schizophr Bull. 1987;13(2): 261-76.

78 Lovibond SH, Lovibond PF. Manual for the Depression Anxiety Stress Scales. 2nd ed. Sydney, Australia: Psychology Foundation; 1995.

79 Antony MM, Bieling PJ, Cox BJ, Enns MW, Swinson RP. Psychometric properties of the 42-Item and 21-Item versions of the Depression Anxiety Stress Scales in clinical groups and a community sample. Psychol Assess. 1998;10(2):176-81.

80 Clara IP, Cox BJ, Enns MW. Confirmatory factor analysis of the depression-anxietystress scales in depressed and anxious patients. J Psychopathol Behav Assess. 2001; 23(1):61-7.

81 Harwood DT, Handelsman DJ. Development and validation of a sensitive liquid chromatography-tandem mass spectrometry assay to simultaneously measure androgens and estrogens in serum without derivatization. Clin Chim Acta. 2009 Nov;409(1-2):78-84.

82 Burger HG. Androgen production in women. Fertil Steril. 2002 Apr;77 Suppl 4:S3-5.
83 Handelsman DJ. Mass spectrometry, immunoassay and valid steroid measurements in reproductive medicine and science. Hum Reprod. 2017 Jun;32(6):1147-50.

84 Handelsman DJ, Wartofsky L. Requirement for mass spectrometry sex steroid assays in the Journal of Clinical Endocrinology and Metabolism. J Clin Endocrinol Metab. 2013 Oct;98(10):3971-3

85 van Rijn S, Aleman A, de Sonneville L, Sprong $M$, Ziermans T, Schothorst $P$, et al. Neuroendocrine markers of high risk for psychosis: salivary testosterone in adolescent boys with prodromal symptoms. Psychol Med. 2011 Sep;41(9):1815-22.

86 Riecher-Rössler A. Oestrogens, prolactin, hypothalamic-pituitary-gonadal axis, and schizophrenic psychoses. Lancet Psychiatry. 2017 Jan;4(1):63-72.

87 Riecher-Rössler A, Häfner H, Stumbaum M, Maurer K, Schmidt R. Can estradiol modulate schizophrenic symptomatology? Schizophr Bull. 1994;20(1):203-14.

88 Bundy H, Stahl D, MacCabe JH. A systematic review and meta-analysis of the fertility of patients with schizophrenia and their unaffected relatives. Acta Psychiatr Scand. 2011 Feb; 123(2):98-106.

89 Paipa N, Stephan-Otto C, Cuevas-Esteban J, Núñez-Navarro A, Usall J, Brébion G. Second-to-fourth digit length ratio is associated with negative and affective symptoms in schizophrenia patients. Schizophr Res. 2018 Sep;199:297-303.

90 Adhya D, Annuario E, Lancaster MA, Price J, Baron-Cohen S, Srivastava DP. Understanding the role of steroids in typical and atypical brain development: advantages of using a "brain in a dish" approach. J Neuroendocrinol. 2018 Feb;30(2):e12547.

91 Hietala M, Sandberg T, Borg A, Olsson H, Jernström $\mathrm{H}$. Testosterone levels in relation to oral contraceptive use and the androgen receptor CAG and GGC length polymorphisms in healthy young women. Hum Reprod. 2007 Jan;22(1):83-91.

92 Kang MJ, Lee JS, Kim HY, Jung HW, Lee YA, Lee SH, et al. Contributions of CAG repeat length in the androgen receptor gene and androgen profiles to premature pubarche in Korean girls. Endocr J. 2017 Jan;64(1):91-102.

93 Karlson EW, Chibnik LB, McGrath M, Chang $\mathrm{SC}$, Keenan BT, Costenbader KH, et al. A prospective study of androgen levels, hormonerelated genes and risk of rheumatoid arthritis. Arthritis Res Ther. 2009;11(3):R97.
94 Zuloaga DG, Morris JA, Jordan CL, Breedlove SM. Mice with the testicular feminization mutation demonstrate a role for androgen receptors in the regulation of anxietyrelated behaviors and the hypothalamicpituitary-adrenal axis. Horm Behav. 2008 Nov;54(5):758-66.

95 Zuloaga DG, Poort JE, Jordan CL, Breedlove SM. Male rats with the testicular feminization mutation of the androgen receptor display elevated anxiety-related behavior and corticosterone response to mild stress. Horm Behav. 2011 Sep;60(4):380-8.

96 Wainwright SR, Workman JL, Tehrani A, Hamson DK, Chow C, Lieblich SE, et al. Testosterone has antidepressant-like efficacy and facilitates imipramine-induced neuroplasticity in male rats exposed to chronic unpredictable stress. Horm Behav. 2016 Mar; 79:58-69.

97 Snyder PJ, Bhasin S, Cunningham GR, Matsumoto AM, Stephens-Shields AJ, Cauley JA, et al.; Testosterone Trials Investigators. Effects of Testosterone Treatment in Older Men. N Engl J Med. 2016 Feb;374(7):61124.

$98 \mathrm{Xu} \mathrm{L}$, Freeman G, Cowling BJ, Schooling $\mathrm{CM}$. Testosterone therapy and cardiovascular events among men: a systematic review and meta-analysis of placebo-controlled randomized trials. BMC Med. 2013 Apr; 11(1): 108 .

99 Weickert CS, Miranda-Angulo AL, Wong J, Perlman WR, Ward SE, Radhakrishna V, et al. Variants in the estrogen receptor alpha gene and its mRNA contribute to risk for schizophrenia. Hum Mol Genet. 2008 Aug; 17(15):2293-309.

100 Azcoitia I, Yague JG, Garcia-Segura LM. Estradiol synthesis within the human brain. Neuroscience. 2011 Sep;191:139-47.

101 Vermeulen A, Verdonck L, Kaufman JM. A critical evaluation of simple methods for the estimation of free testosterone in serum. J Clin Endocrinol Metab. 1999 Oct;84(10): 3666-72.

102 Taylor AE, Keevil B, Huhtaniemi IT. Mass spectrometry and immunoassay: how to measure steroid hormones today and tomorrow. Eur J Endocrinol. 2015 Aug; 173(2):D1-12.

103 Tsai SJ, Hong CJ, Liao DL, Chiang CH. Distribution of androgen receptor CAG repeat polymorphism in Chinese schizophrenia and its correlation with age at onset. Psychoneuroendocrinology. 2006 Feb;31(2):270-4. 